\title{
TRABALHO E SOBREVIVÊNCIA - o mundo da vida sob ameaça: racionalidade ou irracionalidade?
}

\author{
Silvia Maria de Araújo* \\ Daniel Lopes Cianalli**
}

\begin{abstract}
Resumo: A condução da vida por uma racionalidade capitalistainstrumental é o tema aqui discutido sob o prisma de reconhecê-la em manifestações da vida, sem desconhecer o quanto afeta o chamado mundo do trabalho. A subjetividade comprometida do trabalhador nesse processo é um dos seus maiores efeitos. A construção do texto resgata as idéias weberianas sobre um processo racionalinstrumental que absorve a vida moderna, apresentando, em seguida, o novo paradigma habermasiano da razão comunicativa como alternativa às conseqüências dessa lógica tipicamente capitalista. Ao analisar a invasão do mundo sistêmico sobre o mundo da vida e a continuidade desse processo, o artigo elabora uma reflexão sobre a racionalidade, colocando a indagação: nas condições da moderna produção flexível, marca das grandes e médias indústrias de caráter transnacional, está-se diante de uma racionalidade ou irracionalidade capitalista?
\end{abstract}

Palavras-chave: racionalidade, mundo do trabalho, mundo da vida, subjetividade.

\section{Introdução}

Saber se a vida cotidiana corre sobre uma base racional ou irracional é a questão que este trabalho se propõe a desvendar.

* Socióloga, professora do Programa de Pós-Graduação em Sociologia da Universidade Federal do Paraná (UFPR), pós-doutora pela Università degli Studi di Milano. E-mail: saraujo@swi.com.br

**Programador de Informática, Mestrando do Programa de Pós-Graduação em Sociologia da UFPR.E-mail: danielc@sofhar.com.br

Artigo recebido em 15 fev. 2005; aprovado em 24 mar. 2006. 
Por meio de críticas e análises sobre as relações entre o mundo da vida e o mundo sistêmico, busca-se a reflexão sobre o que seria racional ou ato de irracionalidade no comportamento cotidiano das organizações e indivíduos. A discussão se inicia com um resgate das idéias de Weber sobre racionalidade e sua preocupação em explicar a existência de um processo racional instrumental que comanda a vida moderna.

$\mathrm{Na}$ seção seguinte, é realizado um contraponto com o racionalismo instrumental weberiano por meio do paradigma da razão comunicativa proposto por Habermas. $\mathrm{O}$ foco, antes apontado para o processo histórico de racionalização econômica e administrativa em si, é direcionado para uma alternativa aos efeitos desse processo sobre o trabalho.

Em seguida, apresenta-se o papel exercido pela ciência e, sobretudo, pela técnica moderna, sobre a racionalidade do homem. Parte-se da ligação estabelecida entre ciência e técnica, sobreposta no século XX pela relação entre ciência e tecnologia que, liderada pelos interesses do capital, transforma o mundo do trabalho e o mundo da vida. Esses são vividos e percebidos como mundos separados, repletos de relações sociais complexas, marcadas por um sistema mecânico de impessoalidade e "coisificado".

Vencidas as digressões propostas, a última sessão apresenta os efeitos ameaçadores do mundo sistêmico sobre o mundo da vidatrabalho, pela ótica de Habermas.

\section{A racionalidade em Weber}

Gerth e Mills (1968) mantêm um ponto de vista que opõe as idéias de Marx (2002)e Weber (1977, 2002), possibilitando introduzir esse assunto de forma apropriada. A argumentação prende-se à idéia de que, para Marx, a economia moderna é irracional, enquanto para Weber, além do capitalismo moderno não ser irracional, as suas instituições seriam "a materialização mesma da racionalidade" (Weber, 1977, p. 66). Entretanto, o que os autores apontam como irracionalidade em Marx deve ser visto em outra perspectiva. 
O capitalismo seria irracional por se tratar de uma contradição entre as forças produtivas e as relações de produção com efeitos sobre a sociedade. As conseqüências de um progresso técnico racional a favor das forças produtivas e avessas ao desenvolvimento da vida humana seriam provas suficientes de que não se trata de uma racionalidade, mas de uma irracionalidade, ao não considerar os efeitos sobre o mundo vivido e seus produtores, os homens. Há em Marx, a consciência de que o capitalismo se move por meios racionais de interesses dos proprietários dos meios materiais de produção. A sua crítica, entretanto, atinge o resultado dessa racionalidade ${ }^{1}$. Ocorre uma focalização de abordagens diferentes entre os dois autores clássicos. Uma vez que Marx se preocupa com os efeitos sobre a sociedade de uma racionalização que se mostra irracional, Weber procura demonstrar a existência de um processo racional instrumental que absorve e comanda a vida moderna.

As diversas formas das organizações sociais são a expressão de como, na sociedade contemporânea, a racionalidade se torna um valor ou uma norma, capaz de conformar indivíduos e grupos, moldando classes sociais, aprisionando-as com seu poder ideológico. A racionalidade do agir econômico é uma formação histórica que se identifica com o desenvolvimento do capitalismo. A concepção de racionalidade técnica diz respeito à lógica racional orientada pelos procedimentos técnicos. De qualquer modo, a técnica responde a uma necessidade, demanda ou exigência histórica de um grupo ou de segmentos de uma estrutura social. Embutidas na concepção de técnica estão as noções de invenção, inovação e progresso técnico próprias de cada cultura, no caso, a capitalista. Do ponto de vista sociológico, a invenção de uma técnica é menos relevante que a sua adoção e difusão em uma coletividade, a inovação.

A racionalidade apresenta-se, no plano do conhecimento, como o fenômeno da ciência que desmitificou o mundo, ou seja, ela substituiu a revelação e muitas explicações de caráter mítico por explicações racionais ou científicas. Pode-se dizer que foi esse ethos da sociedade tecnológica em nascimento que levou Weber a opor a racionalidade ao tradicionalismo. 
Entender como se constitui essa racionalidade, que data o início da modernidade e se sustenta até hoje, é pré-requisito para se discutir seus efeitos sobre a sociedade e o mundo da vida, plenos de significados elaborados na convivência.

A racionalidade funda-se na convicção de que as coisas encontram a sua explicação nelas próprias e não no exterior, no mito ou na tradição. Decorre daí, o fenômeno do trabalho com ênfase na racionalidade técnica. O trabalho explica-se por si, pelo mundo que cria em função da atividade produtiva. No plano da ação prática, a racionalidade implica a investigação constante dos meios mais objetivamente eficazes com vista a fins definidos como realizáveis. Nesse processo, não se apresenta o trabalho como uma atividade prática por excelência, a ação criativa capaz de produzir valor? As finalidades e os meios que justificam a racionalidade técnica não são encarados como adquiridos, mas estão sujeitos a constantes revisões, que recolocam a questão. Essa atitude mental esteve na origem da revolução industrial e do progresso técnico e científico, persistindo no capitalismo atual.

Segundo Weber (2002), a ânsia pelo lucro e o ganho materialfinanceiro existiram em outras épocas e não constituem características próprias do ocidente. Mercadores árabes, comerciantes indianos e chineses exerciam suas atividades objetivando o lucro e, no entanto, esse comportamento não é identificado com o capitalismo. $\mathrm{O}$ que fez o capitalismo se diferenciar das atividades "pré-capitalistas" foi a conduta racional, a organização do trabalho, a persecução do dinheiro, ao invés da aventura. Ou seja, para Weber, o capitalismo "identifica-se com a busca do lucro, do lucro sempre renovado por meio da empresa permanente, capitalista e racional" (p. 26). A constituição da empresa e de sua diligência racional com o capital tornou-se o diferencial no sistema ocidental moderno, que tomou as atividades econômicas como inofensivas na esfera social.

Weber classificou o comportamento burguês de "espírito capitalista", um ethos de valores culturais, capaz de levar ao lucro por meio de um planejamento de meios e fins, associado ao trabalho 
persistente e contrário ao usufruto da receita obtida. Esse "espírito" estaria presente em estado potencial de desenvolvimento como um tipo ideal de conduta nos representantes da ascese puritana calvinista, geradora de preceitos morais controladores do corpo e do espírito. A busca racional do ganho, culturalmente, criou o capitalismo no ocidente.

As atividades das empresas modernas podem ser vistas, na teoria weberiana, como ações econômicas e administrativas racionais com relação a fins. Dessa maneira, após a organização em termos capitalistas da produção, a instauração de uma administração organizada em termos burocráticos foi a seqüência natural para o desenvolvimento do capitalismo atual. A burocracia, mais propensa às ações do Estado, é adotada também pelas empresas, com a missão de colocar em prática uma organização baseada em especializações de funções administrativas, harmonizadas com finalidades objetivas (Weber, 1968).

Ao se tomar o processo de burocratização como conseqüência de um desenvolvimento da racionalização - um aparato de adequação dos meios para alcançar os fins estipulados pela organização empresarial -, percebe-se em sua estrutura a predominância de uma lógica que coíbe governos pessoais por uma atitude racional e solidária aos interesses da empresa. Arendt (2003, p. 55) define a burocracia como a "substituição do governo pessoal pela burocracia que é o governo de ninguém". Leia-se impessoalidade, como se a administração e o trabalho fluíssem por processos racionais de vida própria, dos quais se valem os interesses econômicos da empresa e que podem se livrar dos vínculos pessoais, empecilho aos empenhos capitalistas.

Assim, para Weber, o progresso da racionalidade sobre nosso mundo é indissociável do desenvolvimento das organizações, da burocracia, do Estado, do capitalismo em essência. Elementos que comprovam o aspecto racional interiorizado no mundo ocidental, e que se mantêm até os tempos contemporâneos, são identificados por 
Carvalho (1999, p. 2) como "o surgimento do cálculo racional dos custos da produção, a institucionalização do trabalho assalariado, o aparecimento de uma nova maneira de pensar e de agir que favorecia o processo de acumulação, a contínua incorporação da ciência e da técnica ao processo produtivo, a modificação do Estado".

Os estudos sociológicos têm dado pouca atenção à técnica em geral, concentrando-se sobre a tecnologia moderna, entendida como aplicação da ciência à técnica de produção e organização industrial e de projeto de produtos, cuja expressão pode ser ilustrada pela automação. Quando a técnica é aplicada instrumentalmente na busca de um melhor resultado - como: volume, qualidade, quantidade, economia de tempo e recursos ou, mesmo, de um resultado, algumas vezes, irrealizável -, diz-se da obtenção de um progresso técnico. O capitalismo, por exemplo, como uma ação racional, para poder se firmar, teve necessidade da adoção generalizada de técnicas de mensuração do tempo, de técnicas do direito e da administração (Gallino, 1993, p. 686-690).

Embora nas seções finais deste texto sejam comentados de maneira detalhada os efeitos dessa racionalização sobre o mundo da vida, cabe mencionar aqui alguns deles. A utilização do conhecimento científico e técnico, sobretudo no processo administrativo e produtivo, foi incentivada por considerações econômicas racionais da empresa. Esse ambiente estimulou o fortalecimento da esfera racional, técnica e científica e, nesse contexto, as relações pessoais, culturais e de trabalho não sobrevivem sem sofrer alguma alteração.

A divisão do trabalho adequada aos interesses capitalistas e aliada ao aparato técnico-científico forma um complexo de relações que fere a liberdade do ser humano (Carvalho, 1999; Habermas, 1988; Weber, 2002). A padronização de rotinas e procedimentos produtivos ou administrativos transforma o indivíduo em uma engrenagem ou mero ocupante de um cargo, ao invés de um ser dotado de criatividade, sentimento e vontade. O paradoxal desse comportamento é que essas são as competências cobradas do 
trabalhador, na atualidade. A impessoalidade nas relações de trabalho produz "profissionais deploráveis, carentes de heroísmo, espontaneidade humana e inventividade", afirmam Gerth e Mills (1968, p. 68), reduzindo a participação do trabalhador a um simples fator de produção. Daí, a expressão "recursos humanos", criticada por Gorz (2003, p. 71) como a imagem da empresa transformada em lugar de aperfeiçoamento pessoal para seus assalariados.

Qualquer intenção que contradiga o percurso dessa racionalidade técnica instrumental adaptada à esfera administrativa é coibida com uma contra-ameaça sobre o seu emprego e a permanência do trabalhador no mundo do trabalho. O jogo capitalista não deixa outra saída ao trabalhador remunerado de qualquer nível: adaptarse, subordinando-se às regras dessa forma de produzir, intensificada com a mudança para o paradigma produtivo da acumulação flexível (Harvey, 2002). A possibilidade de exclusão do mercado de trabalho passa a ser uma nova forma de servidão que aprisiona o homem à sua sobrevivência e à de seus dependentes, gerando apreensão e sofrimento também para aqueles que, empregados, temem a competição e a demissão (Dejours, 2003).

A racionalidade intrínseca ao capitalismo e que se mostra invasiva em diferentes redutos da vida causou dúvidas sobre seus benefícios ao próprio Weber que, em $A$ ética protestante e o espírito capitalista, teceu opinião sobre questão que ainda perturba os estudiosos, ou seja, a apreensão dessa realidade invertida: "parece por demais irracional esse tipo de vida em que o homem existe para o seu negócio, quando deveria ser o contrário" (Weber, 2002, p. 61).

A razão "secularizou" e "desenfeitiçou" as imagens do mundo, segundo Habermas (1975), ao romper, em primeiro lugar, com um comportamento produtivo-administrativo-cultural enraizado no tradicionalismo ${ }^{2}$ e substituir atitudes racionais com relação a valores por um comportamento em relação a fins. Em segundo lugar, a lógica racional embrutece, tirando dos indivíduos a espontaneidade, incentivando-os à participação por meio de 
ideologias e formas coercitivas no jogo capitalista; submete-os a uma sociedade de excedentes que valoriza o capital antes da vida, valorizando a vida somente como produtora de capital. Frente à dura sobriedade experimentada pelos trabalhadores em tempos de racionalidade, transparecem aqui os primeiros questionamentos sobre uma irracionalidade travestida de racionalidade, ainda sustentada empírica e analiticamente.

\section{O paradigma habermasiano da ação comunicativa}

Embora Weber tenha compreendido a racionalidade que se alastrou e se fixou no mundo, a sua teoria sofreu críticas de diversos pensadores. É inegável, entretanto, o terreno desbravado por seus estudos. Reis (1999) assinala, por exemplo, uma unilateralidade instrumental na teoria weberiana, um excesso de atenção aos aspectos econômicos e políticos do capitalismo, negligenciando aqueles sociais e humanos no processo racionalista. Na tradição analítica de um neo-frankfurtiano, Habermas (1988), por outro lado, discute a sociedade pela visão de duas razões: a instrumental e a comunicativa. Ao criticar a razão instrumental weberiana, propõe um novo paradigma, ou seja, uma racionalidade comunicativa, baseada em aspectos prático-morais da comunicação humana.

De maneira geral, a razão é criticada por conter poder e ser fonte de dominação. ${ }^{3}$ Tanto Horkeimer quanto Adorno, viam na possibilidade libertadora uma "ilusão iluminista", um sinônimo de "reificação, de exercício de poder e de barbárie", conforme Medeiros (2003, p. 9), para quem Adorno, inclusive, "aniquila a razão, quando a põe a serviço da dominação". Pelos estudiosos, a racionalização é travestida de uma forma de dominação política, o "exercício do controle" e do poder, em versão atualizada e crítica de Habermas (1975, p. 304). A dominação passa a ser legitimada pelo capitalismo e suas relações de produção. Assim, a ciência, com seus instrumentos para o controle da natureza e do próprio homem, o comportamento do mercado e as forças 
ideológicas do stablishment maquiam a utilização do poder e da dominação pela racionalidade.

Habermas (1975) sustenta que a sociedade consiste num mundo sistêmico, onde prevalecem as regras e relações do mercado e do Estado, e um mundo vivido. Feenberg (2004b) argumenta que Habermas desmitifica a ação racional em relação a fins quando subtrai dela seu real objetivo de controlar e "tecnicizar" o mundo da vida. Este, por sua vez, sendo considerado o ambiente cotidiano onde os indivíduos agem e se defrontam com suas ações, relações sociais, interpessoais e subjetivas, é passível dessa influência racional. Os homens deixam de preservar o mundo da vida. Ocorre a sua sujeição à objetividade racional da vida social moderna exposta e perseguidora de interesses materiais e materialistas.

Para precisar a influência do progresso técnico e científico no quadro institucional em vias de modernização, Habermas (1975) propõe categorias de análise diferentes das de Weber e Parsons, procurando determinar o significado da racionalidade técnica e científica, como expressão de uma forma de vida específica - a "totalidade histórica" do mundo da vida.

A ciência, a técnica, a razão instrumental, a burocratização e o trabalho organizado de forma racional são exemplos de uma tentativa de colonização e "tecnicização" do mundo vivido, uma tentativa de adaptá-lo ao mundo sistêmico. Os efeitos sobre a sociedade e o homem não podem ser desprezados. Nessa linha, Habermas se refere a uma racionalização comunicativa que pode restabelecer a harmonia do homem consigo e com o mundo, uma troca entre a relação sujeito-objeto pela linguagem-mundo.

A razão comunicativa é a proposta de um paradigma centrado na argumentação e contra-argumentação dos indivíduos, na linguagem, na fala, no consenso e na intersubjetividade posta na relação sujeito-sujeito. É uma razão que caminha à margem da condição instrumental e se baseia no entendimento mútuo de 
ouvintes sobre o mundo objetivo, social e subjetivo. É uma espécie de compartilhar socializado e institucionalizado, ainda que o autor coloque o consenso como condição.

Com a ação no plano da comunicação intersubjetiva, ocorre uma mudança de perspectiva: os participantes dessa ação tendem a orientar um enfoque de compreensão dos sujeitos em interação. $\mathrm{Na}$ expressão de Habermas (1990, p. 72):

O agir comunicativo distingue-se, pois, do estratégico, uma vez que a coordenação bem-sucedida da ação não está apoiada na racionalidade teleológica dos planos individuais de ação, mas na força racionalmente motivadora de atos de entendimento, portanto, numa racionalidade que se manifesta nas condições requeridas para um acordo obtido comunicativamente.

Em um certo sentido, a tese de Habermas recupera a subjetividade do indivíduo negada pelo processo unilateral racional e pelo determinismo econômico-administrativo, expresso de forma dominante no determinismo tecnológico que secundariza a lógica social, o humano, desumanizando-o (Araújo et al., 1998).

Dentro da tradição mais recente da Escola de Frankfurt, Habermas concebe a teoria como crítica em relação ao presente, capaz de vislumbrar perspectivas. Ao analisar o papel da ciência e da técnica no capitalismo tardio, demonstra os interesses subjacentes aos projetos científicos e técnicos da sociedade moderna e percebe o progresso técnico-científico como ideologia legitimadora da dominação capitalista. Critica o pensamento positivista de valorização da técnica, pois a sua preocupação é que esse potencial tecnológico em contínuo desenvolvimento, por princípio, não produz, necessariamente, a emancipação humana.

A racionalização institucionalizada da ciência e da técnica constitui o fundamento da legitimação da dominação econômica e política, na medida em que a submissão dos homens a um aparato técnico e científico é apresentada como necessária à promoção do 
bem-estar da população, apesar de perpetuadora de um modo de produção que restringe a liberdade dos próprios homens. Por isso, Habermas opõe-se ao pensamento pessimista de Weber quanto ao processo de racionalização, para quem esse teria acarretado uma perda de sentido na racionalização cultural, em conseqüência do desencantamento das visões tradicionais do mundo e uma perda de liberdade na racionalização social, em função da burocratização do Estado e da economia, segundo Rouanet (1987).

A proposta de Habermas (1990) é uma tentativa de responder à interpretação weberiana da racionalidade sem saída, que legou uma visão técnica-instrumental integrada à ordem dominante. A economia capitalista tende a dirigir a sociedade para uma existência menos socializada, destruidora da intersubjetividade. A sugestão de uma racionalidade plantada na comunicação lança luz para combater a tendência à contração do mundo da vida e resgatar o social compartilhado.

\section{Ciência e tecnologia dominantes}

A era da informação e do conhecimento marca a sociedade contemporânea e a conduz por um caminho onde ciência e tecnologia agem interativamente sobre uma diversidade de ambientes, como, por exemplo, o mundo do trabalho. A tecnologia da informação - que para Castells (2000) se constitui em sistemas de informação -, interage com o ambiente das empresas capitalistas, ultrapassa-o e, simultaneamente, responde por mudanças na estrutura dos setores econômicos tradicionais, nas forças competitivas e nas relações entre escala de produção e automação. O componente novo e cada vez mais persistente da flexibilidade entre os sistemas atinge, em conseqüência, os indivíduos e suas relações não apenas contratuais formais mas, também, subjetivas. A sua aplicabilidade impõe-se como um dos itens do desenvolvimento produtivo desde a segunda metade do século XX.

Para entender os efeitos causados pela combinação ciênciatécnica é preciso compreender esse entrelaçamento, segundo Corrêa 
(1997). A ciência se constitui no conhecimento da realidade por meio de teorias, enquanto a técnica mede a relação homem e natureza, responsável pela transformação do real, pelo modo de fazer alguma coisa, pela produção de bens e serviços. Ciência e técnica são partes em interação; utiliza-se a ciência para se criar tecnologia e esta influencia o andamento daquela. A ciência produz tecnologia e, simultaneamente, é produzida pela técnica. Nesse jogo imbricado, a retroalimentação entre ciência e tecnologia cria um ambiente propício a benefícios recíprocos. Cabem, entretanto, questionamentos: Quais são os seus efeitos sobre o mundo vivido? Em que medida o progresso tecno-científico e o crescimento econômico afetam o sistema social para alavancar condições de vida melhores e extensivas? Qual é a linha desses avanços?

O fio condutor do desenvolvimento científico-tecnológico é delineado pelo interesse capitalista, uma vez que "as ciências modernas servem ao progresso técnico, ao fomento do crescimento capitalista e à administração racional", afirma Habermas (1988, p. 465). Também Weber (2002, p. 31), a seu tempo, debitava responsabilidade à utilização técnica do conhecimento científico, considerada importante para as condições de vida do povo e, certamente, era "incentivada pelas considerações econômicas". Deduz-se que o avanço científico e técnico está associado a uma racionalização em benefício capitalista, exclusiva do capitalismo. Os laboratórios farmacêuticos, por exemplo, priorizam pesquisas científicas de medicamentos que podem atingir o mercado consumidor, ou seja, para serem comercializados com lucro elevado. Também, a produção e o emprego de armamentos mais sofisticados, eficazes e violentos, o desenvolvimento de técnicas para controle do trabalhador, a intensificação do trabalho por meio de máquinas modernas e outros artifícios favorecem a extração da mais-valia relativa $^{4}$ e fazem avançar a tecnologia com efeitos destruidores.

Como o modo de produção capitalista requer uma ampliação contínua das forças produtivas, a introdução de novas tecnologias 
e estratégias é institucionalizada, ampliando-se a esfera dos subsistemas do agir racional com respeito a fins, rebaixando a supremacia tradicionalista do quadro institucional, na visão de Habermas (1975). Ao tecer a distinção entre "trabalho" e "interação", procura caracterizar as mudanças estruturais no quadro institucional da sociedade tradicional em transição para uma sociedade moderna. Sendo o trabalho o agir racional com relação a fins (agir instrumental mais escolha racional) e a interação, o agir comunicativo mediatizado simbolicamente, resultam diferentes sistemas sociais conforme neles predomine uma ou outra forma de agir. A sociedade moderna aponta a possibilidade de a ação racional com respeito a fins colocar em questão os fundamentos cosmológicos da legitimação da dominação.

Da conivência existente entre ciência e tecnologia em favor do capital surgem interferências na subjetividade. A interdependência entre pesquisa e técnica fez da ciência não somente uma força produtiva que transformou a razão do mundo, mas também uma arma de colonização do mundo da vida, argumenta Habermas (1975). Os padrões de ação instrumental não limitam sua atuação aos ambientes administrativos, produtivos e de serviços, mas operam em outros domínios sociais de caráter íntimo dos indivíduos, como, por exemplo, na padronização do desejo de consumir, na urbanização, nos modos de viver, nas formas de comunicação, instituindo um estilo moderno de vida.

Muniz (1995) critica a maneira de produzir mercadorias e a relação homem-natureza como atividades alienadas e desprovidas de racionalidade. Alega que a ciência, a tecnologia e o capital aliados têm o poder de criar uma consciência alienada ou falsa, de tal modo que favorece a transmutação de um mundo de relações sociais complexas e pessoais para um sistema mecânico de relações impessoais adaptável ao capitalismo. Esse mundo tem-se constituído com o apoio de uma racionalidade técnica que procura suprimir a consciência do sujeito, tornando-o volúvel à força das coisas, ao poder material sobre a subjetividade (Araújo, 2003). 
O modo de produção capitalista tem como fundamento de legitimação, num primeiro momento, a promessa de justiça, de equivalência das relações de troca. As novas formas de legitimações que se pretendem científicas, retirando da consciência pública as relações de violência inerentes às trocas no sistema capitalista, constituem ideologias. Cria-se uma segunda natureza de relações e percepções que sobrepuja a histórica relação homem-natureza.

Essa segunda natureza resume-se a uma racionalidade que valoriza o conhecimento, a informação, a ciência e sua aplicação (a técnica) a serviço do capital, de modo que essa composição produz uma maquiagem ideológica para a sociedade capitalista e de consumo, convencendo-a de ser esta uma formação societária natural, singular e benéfica para a maioria dos indivíduos. Hoje, as necessidades e objetivos humanos, o conhecimento científico, as formas de trabalho e o desenvolvimento das forças produtivas estão respaldadas pela forma e conteúdo encontrados nessa segunda natureza, afirma Muniz (1995). Assim, a integração social na segunda natureza é uma alienação dos sentidos que esfuma as intenções capitalistas e "não-sociais", encobrindo as alternativas de uma sociedade justa e integrada ao espírito humano. O problema é que este sentimento de "pertencer" a essa sociedade subtrai dos indivíduos a capacidade crítica de vislumbrar algo diferente, num processo que naturaliza uma situação historicamente construída.

A razão instrumental faz uso da ideologia para legitimar a dominação e o crescimento das forças produtivas. Perseguir uma alta produtividade e um eficaz domínio da natureza traz promessas de recompensas aos trabalhadores: sustento garantido, uma vida pretensamente mais confortável, a diminuição da miséria, o respeito ao meio ambiente. Nem sempre cumpridas, essas promessas fazem proliferar justificativas para o "progresso" capitalista, encobrindo os seus efeitos.

Em A nova intransparência: a crise do Estado de bem-estar social e o esgotamento das energias utópicas, Habermas (1987) 
declara o fim das energias utópicas clássicas e realiza uma análise dos tempos contemporâneos. As expectativas de uma vida digna chocaram-se com uma realidade oposta aos ideais utópicos de trabalho para todos com sentido emancipador. Desemprego, instabilidade, fome são exemplos de problemas antigos potencializados no mundo contemporâneo.

A cientificização da técnica verificada ao final do século XIX indica que o progresso técnico e o progresso científico encontramse em íntima circulação, inseridos no mesmo sistema. Habermas (1975) aponta o fato de o desenvolvimento do sistema social estar determinado pela lógica do progresso técnico-científico, ou seja, atribui-se a este o caráter determinante da manutenção do crescimento econômico. Dessa forma, legitima-se a perda da possibilidade de manifestação da vontade democraticamente formada, substituída pelas decisões tomadas por equipes administrativas. O que se verifica é a substituição progressiva do agir comunicativo pelo agir racional com respeito a fins. A diferença entre uma e outra forma de ação já não é percebida. $\mathrm{O}$ trabalhador é dominado progressivamente por regras técnicas que promovem a sua adaptação a um mundo cada vez menos compreendido por determinações culturais específicas, em função da persistência de modelos científicos e técnicos.

A ciência e a tecnologia como suportes dessa segunda natureza não conseguiram manter seu véu ideológico e deixam transparecer suas conseqüências adversas à natureza, que incluem o homem em uma nova lógica crítica da vida, não mais dicotômica e separatista do raciocínio e percepção de inserção na sociedade (Santos, 1998). As "forças produtivas que se transformam em forças destrutivas", para Habermas (1987, p. 105), perdem sua inocência e produzem efeitos nos diferentes campos da vida. O trabalho amoldado a essa forma de sobrevivência material necessária foge, entre outros sintomas, de suas atribuições à subjetividade, ainda que o discurso enfatize, ad nauseam, o sujeito. Em verdade, o mundo da vida se encolhe frente a essa racionalidade a serviço do capital. 


\section{O mundo da vida ameaçado}

Esta seção discute a interferência do mundo sistêmico sobre o mundo da vida, interpretando-a como uma ameaça, uma espécie de perda do aspecto humano no processo histórico de produção da vida não apenas material. A persistência no pensamento e na ação capitalista de uma racionalidade instrumental posta em tudo traz, como conseqüência, a invasão do ser humano em âmbitos de sua representação simbólica de "estar no mundo". O enfoque unilateral de ações cognitivo-instrumentais acaba produzindo uma reificação da prática cotidiana, ao dominar a consciência dos atores sociais. Como resultado, afasta dos indivíduos o sentido de suas ações, além de mutilar compreensões culturais e sociais em função do clamor pelo pragmatismo, pela aplicação mecanicista do conhecimento, pela necessidade que se impõe de respostas imediatas nas ações.

Habermas (1988) identifica essa neutralização do mundo da vida com uma forma patológica que vem sendo centralizada na vida social. A colonização ou "tecnicização" do mundo traz ameaças de empobrecimento cultural, alienação, destruição de estruturas comunicativas, mecanização das relações intersubjetivas. Há uma percepção de um antes e de um depois,

... não somente o encanto melancólico de algo passado para sempre, não somente o brilho de uma recordação nostálgica de algo que foi sacrificado à modernização sem compensação alguma, senão que, os processos de modernização são vistos seguidos, como por uma sombra, por um instinto (me atreveria a dizer) instruído pela razão, ou, em todo caso, pela sensação de que com a canalização unilateral e a destruição das possibilidades de expressão e comunicação, assim no espaço da vida privada como na esfera da vida pública, se desvanecem as oportunidades de voltar a reunir com naturalidade, em uma prática cotidiana pós-convencional, aqueles momentos que outrora, nas formas tradicionais da vida, constituíram uma unidade. (Habermas, 1988, p. 468).

Além dos efeitos causados pelo acoplamento do caráter capitalista que penetra os poros do social, o mundo da primazia do capital revela os seus problemas ao realizar a reprodução material. 
Como exemplo, tem-se a escassez de matérias-primas renováveis na natureza, a competitividade acirrada de produtos, um mercado consumidor com baixo poder aquisitivo.

O mundo sistêmico expõe a sua malícia no momento em que assenta a proposta de resolução de seus problemas sobre o mundo da vida. Há uma transferência de responsabilidade social para o indivíduo em projetos pessoais ou coletivos; há uma imputação de autoculpa num processo de individualização onde interesses e lucros se tornam sinônimos na sociedade capitalista. Por comodidade, ausência de resistência ou uma voracidade que alimenta as ações racionais orientadas para determinados fins, os desequilíbrios na esfera sistêmica são "resolvidos" com efeitos no mundo vivido pelos homens: resolve-se a escassez dos recursos naturais não renováveis explorando-se mais intensamente a natureza; combatese a competitividade acirrada de produtos com mão-de-obra de baixo custo em outros países ou utilizando-se máquinas e robôs, "soluções" de alta tecnologia.

Ações como essas apenas transferem o problema para outros ambientes e não podem ser tomadas como racionais, pois trazem abalos estruturais à sociedade, à cultura e à personalidade dos indivíduos. Ao invés de uma solução conjunta de problemas, são utilizadas opções capazes de gerar mais vantagem competitiva no mundo sistêmico. Há uma desconfiguração do mundo da vida para solucionar problemas criados pelo próprio sistema capitalista.

São poucas as escolhas. Aos trabalhadores resta adaptaremse a essa forma sutil de dominação. Diante das regras do jogo estipuladas pelo mundo sistêmico, pela força da ideologia dominante, pela alienação decorrente desse processo, pela fraqueza das políticas alternativas, permanece a subordinação ao sistema capitalista em suas diversas feições: trabalho atípico, temporário, precário, terceirizado, quando não, escravo e infantil. Segundo Habermas (1987, p. 105), “as mesmas forças de incrementação do poder - das quais a modernidade extraiu outrora sua autoconsciência e suas expectativas utópicas - na verdade transformaram autonomia em dependência, emancipação 
em opressão, racionalidade em irracionalidade", sentidas na pele pelos integrantes do mundo da vida.

Feenberg (2004b) menciona que Heidegger vê na tecnologia moderna um instrumento destrutivo, justamente pelo fato de os homens serem vítimas de sua própria tecnologia e perderem a visão sobre o que é sacrificado na mobilização do ser humano e dos recursos para objetivos não explicitados. Com base em interpretações como essas é que o presente artigo acusa a racionalidade de estar travestida de irracionalidade.

\section{À guisa de conclusão}

As alternativas que se apresentam são genéricas e generalizáveis. Alguns apostam na auto-realização por meio da riqueza de produção e não pela produção de riqueza alienante e reificada. Nessa proposta, Mészáros (2002, p. 613) admite que a atividade-vital dos indivíduos tem uma finalidade e "pode oferecer uma alternativa viável à cega espontaneidade auto-reprodutiva do capital e suas conseqüências destrutivas. Isso significa a produção e a realização de todas as potencialidades criativas humanas, assim como a reprodução continuada das condições intelectuais e materiais de intercâmbio social".

Habermas (1988) indica a razão comunicativa como um paradigma que pode recuperar a subjetividade do indivíduo, pelo entendimento mútuo de ouvintes sobre o mundo objetivo, social e subjetivo, negada pela exacerbação do processo econômico unilateral racional e pelo determinismo tecnológico. Marcuse (apud Feenberg, 2004a) propõe uma nova ciência e tecnologia que, ao invés do conflito, busquem a harmonia entre a natureza e o homem, numa visão de natureza parceira, integrada ao homem, onde seja possível usufruir de seus recursos de forma consciente, tratando-a como um outro sujeito.

Marcuse critica Weber por utilizar o termo racionalização de maneira puramente formal, apenas para explicar fenômenos 
relacionados com a atividade capitalista, sem levar em conta as implicações econômicas e políticas do agir racional com relação aos fins. Isso refletiria uma conduta de conteúdo ético voltada para a dominação dos homens e da natureza. Concebe, então, a ciência e a técnica, também, como forças produtivas, inseridas no processo capitalista de produção.

Por Marcuse (1967) entender a racionalidade da técnica e da ciência como um padrão em si mesmo indiferente aos fins políticos, vê na mudança de valores que dirigem o progresso técnico e científico, a solução para o problema de a ciência e a técnica servirem como base da dominação sobre os homens e sobre a natureza. Habermas (1975), entretanto, nota que Marcuse não percebe a necessidade de mudar o próprio padrão de racionalidade e não apenas os valores que a orientam, visto que ela está vinculada ao incremento das forças produtivas, as quais legitimam as relações de produção opressoras e restritivas.

Habermas (1987) propõe a tese de que os projetos de formas racionais de vida fundem, em uma síntese ilusória, o controle racional da natureza e a mobilização de energias sociais, uma dessas identificada com a utopia da sociedade do trabalho, que alimentou o desenvolvimento do ocidente. Segundo essa utopia, a razão instrumental originária das forças produtivas em expansão, juntamente com a razão funcionalista, deveria atingir a dimensão emancipatória. É esse esgotamento de uma energia utópica, dada a falência do Estado do bem-estar social, que garantiria o trabalho na forma de emprego, por meio de políticas intervencionistas. Logo, o projeto do Estado social perdeu o trabalho como seu ponto de referência. $\mathrm{O}$ raciocínio prossegue mostrando o pensamento histórico saturado de experiências e descarta o pensamento utópico. Neste limiar do século XXI, predomina a ameaça mundial aos interesses da vida em geral, e, para Habermas (1987, p. 104-105), “o empobrecimento estrutural dos países em desenvolvimento, o desemprego e os desequilíbrios sociais crescentes nos países desenvolvidos, problemas com o meio ambiente sobrecarregado, altas tecnologias operadas às raias da catástrofe, dão as palavras- 
chave que invadiram a consciência pública através dos meios de comunicação de massa". E completa: "as respostas dos intelectuais refletem uma perplexidade não menor que a dos políticos".

Transpostas essas preocupações como utopias que impulsionam a realidade histórica para o plano das interpretações, Habermas (1987) considera a mudança de paradigmas da sociedade do trabalho para a sociedade da comunicação. Para ele, a utopia da sociedade do trabalho perdeu a sua capacidade de persuasão como força estruturadora e socializadora do trabalho abstrato.

Importante marcar que o trabalho abstrato não é uma maneira de reduzir os trabalhos heterogêneos à dimensão comum do tempo, através das relações entre mercadorias do processo de trabalho, mas tem uma existência real na realidade da troca. A abstração que do trabalho incorporado faz trabalho abstrato é uma abstração social, um processo real específico do capitalismo. É apenas no processo de troca que os trabalhos heterogêneos se tornam abstratos e homogêneos e que o trabalho privado se revela social. É o mercado que realiza isso e, portanto, não pode haver uma determinação $a$ priori do trabalho abstrato. A troca é então entendida como uma forma do próprio processo de produção. Não só a abstração surge da realidade da troca, como também o trabalho abstrato é trabalho alienado; a troca é o momento de unidade social sob a forma de eqüalização abstrata ou reificação da força de trabalho na qual a subjetividade humana é expropriada, alerta Colletti (1972, apud Bottomore, 1988, p. 384).

Este texto lança dúvidas à possibilidade de existir uma saída para a racionalidade dominante. Talvez, o seu tom seja pessimista diante do cenário do mundo do trabalho. Haveria outra maneira de se conduzir a produção e obter benefícios para a população, sem que esta sucumba aos efeitos do capitalismo atual sobre o mundo da vida? Seria possível uma união entre a vida e o sistema para a resolução efetiva de problemas no mundo? Poderia o trabalho deixar de ser uma atividade despersonalizada e inorgânica e ser devolvido ao homem, em suas características de construtor do sujeito? Haveria 
possibilidade do trabalhador ser realmente sujeito do trabalho? O trabalho poderia ser colocado a serviço do homem?

Alguns desses questionamentos são respondidos de forma direta, outros indiretamente. O mais importante é, talvez, a crítica feita a esse processo que aparenta estar "naturalizado" e que conduz e controla os meios de vida. Fica a impressão de um despertar abrupto para o que acontece no mundo, embora a problemática seja antiga com roupagens novas. Para o mundo do trabalho, essas idéias críticas concretizam uma ponte para a construção de um mundo justo e digno para os seres humanos e não apenas um mundo racional ou irracional.

\section{Notas}

1 Racionalidade é um atributo variável da ação humana e diz respeito a algum objetivo, interesse ou valor perseguido pelo sujeito agente em condições como: levar em conta o exame das alternativas possíveis na situação; individualizar as variáveis externas que possam influenciar os resultados da ação, calculando a alternativa mais provável; avaliar com método as conseqüências das diversas alternativas; ponderar de modo comparativo a utilidade e o valor de qualquer conseqüência; otimizar a utilidade e o valor máximo (não importa se econômico, afetivo, político ou outro) e fazer disso objeto de critérios de decisão; encarar a ação como algo efetivo e conscientemente empreendido. (Gallino, 1993, p. 531-532).

2 Weber (2002, p. 38) assim se expressa: “antes a forma de organização era capitalista; as atividades do empreendedor tinham um caráter puramente comercial; o uso do capital investido, o negócio era indispensável, e, finalmente, o aspecto objetivo do processo econômico, a contabilidade, era racional. Mas se consideramos o espírito que animava o empresário, tratava-se de um negócio tradicionalista: tradicional o modo de vida, tradicional a margem de lucro, tradicional a quantidade de trabalho, tradicional o modo de regular as relações com o trabalho". Para Habermas (1975, p. 313), o período onde as tradições culturais, administrativas e produtivas reinavam era mais equilibrado que o momento onde a razão instrumental e econômica predomina: "o esquema estável de um modo 
de produção pré-capitalista, de uma técnica pré-industrial e de uma ciência pré-moderna (...) apesar de progressos consideráveis, nunca atingiram aquele grau de propagação a partir do qual sua racionalidade se torna uma ameaça aberta à autoridade das tradições culturais".

3 Para Weber (1978, p. 117), esses fenômenos são decorrência do ajuste ou reciprocidade nas relações sociais, pois "poder é a oportunidade (...) que permite a um sobrepor sua vontade sobre o outro mesmo contra resistência", enquanto, dominação "é a oportunidade de ter um comando obedecido por um grupo dado de pessoas". A diferença é de grau na relação.

4 A mais-valia relativa "é a mais valia decorrente da contração do tempo de trabalho necessário e da correspondente alteração na relação quantitativa entre ambas as partes componentes da jornada de trabalho" [trabalho necessário e trabalho excedente], para Marx (2002, p. 366). Assim, ao se fixar o tempo da jornada de trabalho, o tempo de trabalho necessário reduz-se frente ao crescimento do tempo de trabalho excedente.

Work and survival - the world of life under menace: rationality or irrationality?

Abstract: The instrumental-capitalist rationality that occupies the world of life is here discussed in a labor's point of view. The commitment of worker's subjectivity is one of the biggest results of the technological, technical and scientific transformation occurred in the last century and it is disposed to the capitalist accumulation, moreover after the adoption of the flexible production method. The modern automotive industry assembled in Curitiba, since the beginning of the year 1990, is one of this transitions example. The intense social transformations of the last three decades in the world of work were provoked by the innovations in the labor and production organization area. The text begins with a discussion of Weber ideas about a rational-instrumental process that emerges in modernity, presents Habermas's communicative paradigm proposition as an alternative to the consequences of this hegemonic logic. Analyzing the advancement of the systemic world over the world of life, this paper builds up a critic to the instrumental right and opens the 
question of whether all this is the result of a rational or irrational capitalism. Theory and interviews with workers support the answers developed in this article.

Key-words: world of work, world of life, subjectivity.

\section{Referências bibliográficas}

ARAÚJO, S. M. de et al. O trabalho subvertido no jogo capitalista: a racionalidade técnica e a lógica social. História: Questões \& Debates, v. 15 , n. 29, p. 59-82, ago./dez. 1998.

ARAÚJO, S. M. de. As várias faces da ideologia. In: CORREA, A. (Org.). Para filosofar. 4. ed. São Paulo: Scipione, 2003. p. 145-172.

ARENDT, H. A condição humana. 10. ed. Rio de Janeiro: Forenze Universitária, 2003.

BOTTOMORE, T. (Org.) Dicionário do pensamento marxista. Rio de Janeiro: Zahar, 1988.

BOURDIEU, P. A economia das trocas simbólicas. São Paulo: Perspectiva, 1974.

CARVALHO, A. B. Puritanismo e racionalização do mundo: a perspectiva weberiana. São Paulo, 14 f. Relatório - Departamento de Educação, UNESP - Assis, 1999.

CASTELLS, M. A sociedade em rede. 3.ed. São Paulo: Paz e Terra, 2000.

CORRÊA, M. B. Tecnologia. In: CATTANI, A. (Org). Trabalho e tecnologia: dicionário crítico. Petrópolis: Vozes, 1997. p. 250-257.

DEJOURS, C. A loucura do trabalho. São Paulo: Oboré, 1987.

. A banalização da injustiça social. Rio de Janeiro: FGV, 2003.

FEENBERG, A. Marcuse or Habermas: two critiques of technology. Disponível em: $<$ http://www-rohan.sdsu.edu/faculty/feenberg/marhab. html $>$ Acesso em: 28 jan. 2004a.

. Heidegger, Habermas, and the essence of technology. Disponível em: <http://www-rohan.sdsu.edu/faculty/feenberg/kyoto. html> Acesso em: 20 jan. 2004b. 
GALLINO, L. Dizionario di Sociologia. Torino: TEA, 1993.

GERTH, H. H.; MILLS, W. (Org). Ensaios de Sociologia. Rio de Janeiro: Zahar Editores, 1968.

GORZ, A. Adeus ao proletariado. Rio de Janeiro: Forenze Universitária, 1982.

GORZ, A. Metamorfoses do trabalho: crítica da razão econômica. São Paulo: Annablume, 2003.

HABERMAS, J. Técnica e ciência como ideologia. In: BENJAMIN, Habermas, Horkheimer, Adorno. São Paulo: Abril Cultural, 1975, p. 303-333. (Coleção Os Pensadores, v. 48)

. A crise de legitimação no capitalismo tardio. Rio de Janeiro: Tempo Brasileiro, 1980.

. A nova intransparência: a crise do Estado de bem-estar social e o esgotamento das energias utópicas. Novos Estudos CEBRAP, n. 18, p. 103-114, set. 1987a.

. Knowledge \& human interest. [Cambridge, UK]: Polity Press, 1987b. Cap. 3.

. Teoria de la accion comunicativa: tomo II, critica de la razón funcionalista. Madrid: Taurus, 1988.

. Pensamento pós-metafísico. Rio de Janeiro: Tempo Brasileiro, 1990.

HARVEY, D. Condição pós-moderna: uma pesquisa sobre as origens da mudança social. 11.ed. São paulo: Loyola, 2002.

HEMEROTECA VIRTUAL ANUIES. Estudios filosofia-história-letras. Racionalismo y politeísmo de valores. 1988. Disponível em: $<\mathrm{http} / / /$ www.hemerodigital.unam.mx/ANUIES/ itam/estudio/letras15/texto $1 / \mathrm{sec} \_2 . h t m l>$ Acesso em: 5 fev. 2004.

LESSA, S. Mundo dos homens: trabalho e ser social. São Paulo: Boitempo, 2002.

MERCUSE, H. Ideologia da sociedade industrial. Rio de Janeiro: Zahar, 1967.

MARX, K. O capital: crítica da economia política. 19. ed. Rio de Janeiro: Civilização Brasileira, 2002. Livro 1. 
MEDEIROS, A. M. S.; MARQUES, M. Habermas e a teoria do conhecimento. Educação Temática Digital, v. 5, n. 1, p. 1-24, dez. 2003.

MÉSZÁROS, I. Para além do capital: rumo a uma teoria de transição. São Paulo: Boitempo; Editora da UNICAMP, 2002.

MOTIM, B. M.; ARAÚJO, S. M. de et al. O trabalho subvertido no jogo capitalista: a racionalidade técnica e a lógica social. História: Questões \& Debates, Curitiba, v. 15, n. 29, p. 59-82, ago./dez. 1998.

MUNIZ, J. N. O conhecimento científico como falsa consciência necessária. Cadernos de Ciência \& Tecnologia, Brasília, v. 12, n. 1/3, p. 29-38, 1995.

REIS, F. W. Racionalidade não discursiva? Resenha de Jessé Souza, Patologias da modernidade: um diálogo entre Habermas e Weber. Revista Brasileira de Ciências Sociais, v. 14, n. 39, p. 177-178, fev. 1999.

ROIO, M. Política operária: há futuro. Disponível em: $<$ http://www.obore.com/artigos/mostra_artigo.asp?codigo $=17>$ Acesso em: 11 out. 2003.

ROUANET, S. Razão negativa, razão comunicativa. In: . As razões do Iluminismo. São Paulo: Companhia das Letras, 1987,

SANTOS, B. S. Um discurso sobre as ciências. 10. ed. Lisboa: Afrontamento, 1998.

SILVA, S. L. Razão instrumental e razão comunicativa: um ensaio sobre duas sociologias da racionalidade. Trabalho acadêmico. Programa de Pós-graduação Interdisciplinar em Ciências Humanas, UFSC, Florianópolis, 2001. 9 p.

WEBER, M. Burocracia. In: GERTH, H. H.; MILLS, W. (Org). Ensaios de Sociologia. Rio de Janeiro: Zahar, 1968.

. Economía y Sociedad. Bogotá: Fondo de Cultura Económica, 1977.

. Basic concepts in Sociology. London: Peter Owen, 1978.

. A ética protestante e o espírito do capitalismo. São Paulo: Martin Claret, 2002.

. El desarrollo de la ideología capitalista. Disponível em: $<\mathrm{http}: / /$ www.forum-global.de/soc/bibliot/weber/weberdesareconcapit. htm> Acesso em: 2 fev. 2004. 